\title{
Tumour location affects the incidence of cataract and retinopathy after ophthalmic plaque radiation therapy
}

\author{
Paul T Finger
}

\begin{abstract}
Aim-To examine how tumour location affects ocular morbidity after ophthalmic plaque radiotherapy for uveal melanoma. Methods-69 eyes were irradiated and followed for a mean 42 months. There were 23 anterior uveal melanomas and 46 were posterior to the equator. Anterior and posterior tumours had similar basal dimensions. Their mean apical heights were $4.8 \mathrm{~mm}$ (anterior) and $3.5 \mathrm{~mm}$ (posterior) which received a mean $88 \mathrm{~Gy}$ and $83.4 \mathrm{~Gy}$ respectively.

Results-Only one patient (4\%) plaqued for an anterior uveal melanoma developed secondary retinopathy (cystoid macular oedema). In contrast, $24(52 \%)$ of the posterior choroidal melanoma patients developed retinopathy ( $p$ value $<0.0001)$. Cataract developed in $18(86 \%)$ eyes with phakic anterior tumour compared with seven $(17 \%)$ eyes with posterior tumours (p value $<0.0000$ ). No posterior nasal tumours lost more than two lines of vision though $45 \%$ developed retinopathy.

Conclusion-While plaque radiation of anterior melanomas is more likely to cause reversible vision loss secondary to cataract, treatment of posterior tumours is more likely to be associated with irreversible loss because of retinopathy. Nasal location is also protective against severe loss of vision.
\end{abstract}

(Br f Ophthalmol 2000;84:1068-1070)

Enucleation and radiotherapy are the most commonly used treatments for choroidal melanoma. ${ }^{12}$ High energy cobalt- 60 ophthalmic plaques have been replaced by the lower energy ruthenium-106 $\left({ }^{106} \mathrm{Ru}\right)$ and iodine-125 $\left({ }^{125} \mathrm{I}\right) \cdot{ }^{3-7}$ Most recently, palladium-103 $\left({ }^{103} \mathrm{Pd}\right)$ has become available. ${ }^{8-11}$ Though all four radionuclides can be used successfully to treat choroidal melanoma, they differ in their distribution of radiation. ${ }^{12}$

Tumour, and therefore plaque location, affects the distribution of intraocular radiation. Since the plaque is centred over the tumour during treatment, the radiation dose distribution shifts along with the plaque (Fig 1). Treatment of anterior tumours results in a higher dose to the lens, and irradiation of posterior tumours increases the dose to the macula. This study examines tumour location as a risk factor for ocular complications of plaque radiotherapy.

\section{Patients and methods}

PATIENT SELECTION

I report on 69 patients with uveal melanoma. The methods of diagnosis, informed consent, treatment, and follow up have been described. $^{89}$ The basal dimensions of the tumours were determined by ophthalmoscopy, transillumination, fluorescein angiography, and B scan ultrasonography. A scan was also used to measure tumour height. B scan ultrasonography was also used to determine tumour location. Fundus photography with fluorescein angiography was used to evaluate patterns of tumour circulation, focal leakage, cystoid macular oedema (CMO), and radiation retinopathy.

\section{RADIATION TREATMENT}

In a manner similar to the COMS protocol, we calculated the ${ }^{103} \mathrm{Pd}$ seeds as isotropic point sources. No attenuation was attributed to the gold plaque. "Back scatter", as has been noted with ${ }^{125} \mathrm{I}$ plaque radiotherapy, has not been measured with ${ }^{103} \mathrm{Pd}$ and was not used in COMS calculations. ${ }^{1}$

Our surgical techniques of tumour localisation and episcleral plaque insertion have been described. ${ }^{1}$ All patients received one ${ }^{103} \mathrm{Pd}$ brachytherapy session over 5-7 days. Plaque radiotherapy started at insertion and was continued until the prescribed dose was delivered to the tumour's apex. Anterior tumours were treated to an average apex dose of $88 \mathrm{~Gy}$, while the posterior group was calculated to receive 83.4 Gy (5\% less).

\section{Results}

The tumour's base was centred either at or anterior to the equator in 23 eyes, and posterior to the equator in 46 . The average tumour size for the anterior tumour group was $10.5 \times 9 \mathrm{~mm}$ (base) and $4.8 \mathrm{~mm}$ in apical height. Similarly, the posterior tumours averaged $10.3 \times 9 \mathrm{~mm}$ in basal dimension, but they were on average slightly shorter at $3.5 \mathrm{~mm}$ in height and therefore received slightly less radiation.

RADIATION RETINOPATHY

No patients in the anterior tumour group developed, posterior pole haemorrhages cotton wool spots, vascular sheathing, or optic neuropathy. One patient (4\%) plaqued for a 15 $\times 15 \times 8.4 \mathrm{~mm}$ anterior uveal melanoma developed CMO. In contrast, $24(52 \%)$ of the posterior choroidal melanomas developed some form of secondary retinopathy. This dif- 
ference was statistically significant $(\mathrm{p}=$ $<0.0001$ ) Though $45 \%$ of the posterior nasal tumours developed retinopathy none lost more than two lines of vision.

\section{CATARACT}

Eighteen of the 21 phakic patients (85\%) plaqued for anterior uveal melanomas developed a secondary cataract. All but one of the cataract surgeries were performed within the first 3 years of follow up. Eleven of $21(52 \%)$ had predominantly posterior subcapsular cataracts. Eleven patients had cataract surgery, 10 were improved by visual rehabilitation. Overall, four $(17.4 \%)$ of the 23 anterior uveal melanoma patients lost three or more lines of vision at their last follow up examination (mean follow up 3.8 years).

In contrast, only seven (17\%) of the 42 phakic patients with posterior choroidal melanomas developed a significant cataract. This difference was statistically significant ( $\mathrm{p}$ value $<0.0000$ ). Five have undergone surgery (all within the first 2 years of follow up). In contrast to the anterior tumours, four $(80 \%)$ of those patients lost three or more lines of vision despite cataract surgery. Twenty four of 46 $(52 \%)$ have developed some form of posterior segment complication (radiation or tumour related retinopathy, radiation optic neuropathy, cystoid macular oedema, secondary retinal detachment, vitreous haemorrhage). Overall, $48 \%$ of the 46 patients with posterior choroidal melanoma lost three or more lines of vision at their last follow up examination (mean 3.3 years).

\section{OTHER FINDINGS}

One patient from each group required a small prism correction for diplopia, iris neovasculari-

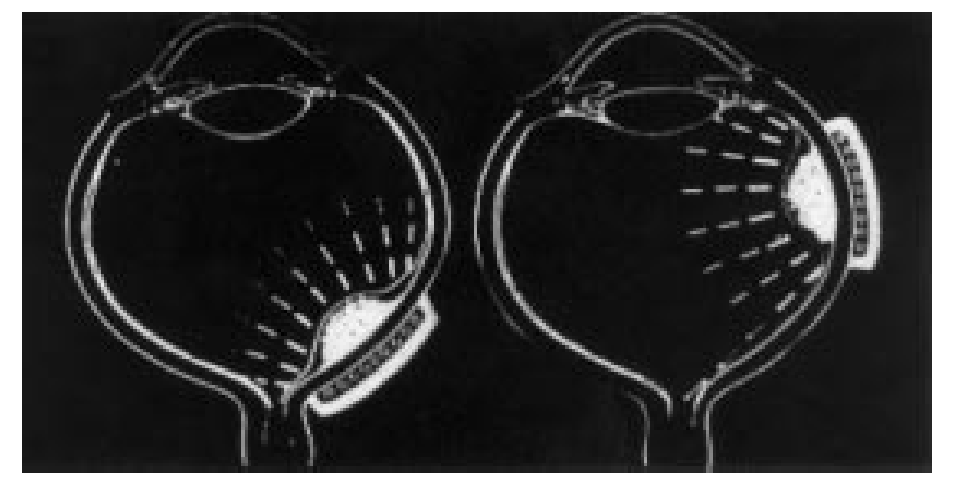

\begin{tabular}{ccc}
\hline Structure & $\begin{array}{c}\text { Anterior position } \\
\text { centred at the ora serrata }\end{array}$ & $\begin{array}{c}\text { Posterior position } \\
\text { 2 mm from fovea and optic nerve }\end{array}$ \\
\hline Lens dose & $55 \mathrm{~Gy}$ & $9 \mathrm{~Gy}$ \\
Foveal dose & $6.7 \mathrm{~Gy}$ & $136 \mathrm{~Gy}$ \\
Optic nerve dose & $6.3 \mathrm{~Gy}$ & $106 \mathrm{~Gy}$ \\
Tumour apex dose & $80 \mathrm{~Gy}$ & $80 \mathrm{~Gy}$ \\
Tumour base dose & $463 \mathrm{~Gy}$ & $463 \mathrm{~Gy}$ \\
\hline
\end{tabular}

Figure 1 Note the shift in radiation distribution when the plaque is either anterior or posterior to the equator. Palladium-103 plaque overlying a hypothetical $10 \times 10 \times 5 \mathrm{~mm}$ choroidal melanoma both treated to an apex dose of 8000 cGy (80 Gy).
Table 1 Incidence of complications after plaque radiotherapy

\begin{tabular}{lll}
\hline Tumour location & Cataract & Retinopathy \\
\hline Anterior & $(18$ of 21$) 85 \%$ & $(1$ of 23$) 4 \%$ \\
Posterior & $(7$ of 42$) 17 \%$ & $(24$ of 46$) 52 \%$ \\
p Value & $<0.0000$ & $<0.0001$ \\
Odds ratio & 30.000 & 0.042 \\
\hline
\end{tabular}

sation occurred twice (solely in the anterior tumour group). No eyelash loss, severe dry eye, or keratopathy was associated with ophthalmic plaque radiation therapy in either group.

\section{Discussion}

Ocular radiation distribution affects the type and incidence of complications. ${ }^{1}$ Treatment of large tumours increases the amount of radiation delivered to all ocular structures resulting in a higher complication rate. ${ }^{12}{ }^{13}$ Charged particle irradiation (proton) typically delivers $70 \%$ of the dose to the anterior segment with a resultant increase in adnexal and anterior segment complications. ${ }^{1415}$ In contrast, the gold of low energy eye plaques protects adnexal structures and is therefore associated with a lower incidence of dry eye and neovascular glaucoma. ${ }^{1}$

In our study, we found that shifting the targeted zone toward the anterior segment all but eliminated the incidence of posterior segment complications while increasing the incidence of cataract (Table 1) Similarly, treatment of tumours located in the posterior nasal quadrant resulted in moving the radiation away from the macula giving less profound vision loss. No clinically significant eyelash loss, keratopathy, or dry eye was found in either group.

The visual prognosis for patients treated with ophthalmic plaque radiotherapy is good for anterior and nasal uveal melanomas and poor for most posterior temporal melanomas. These findings are particularly striking in that the anterior uveal tumours were larger (mean 4.8 versus $3.5 \mathrm{~mm}$ in height) and received a higher radiation dose (a mean 88 versus 83.4 Gy). Both of these facts might have, but didn't, skew the results towards more, not fewer, complications after radiation of anterior uveal melanomas (Table 1).

This study has demonstrated that changing the distribution of radiation dose within the eye, affecting the incidence and location secondary complications. Therefore, techniques focused on decreasing the amount of radiation to normal ocular structures will decrease radiation associated complications..$^{10-22}$ It is hoped that this study has revealed information that may be helpful for patient education and informed consent.

Supported (in part) by the EyeCare Foundation, Inc, New York City, New York, USA (http://www.eyecarefoundation.org).

1 Finger PT. Radiation therapy for choroidal melanoma. Surv Ophthalmol 1997;42:215-32.

Moshfeghi DM, Moshfeghi A, Finger PT. Enucleation. Surv

3 Stallard HB. Malignant melanoblastoma of the choroid. Bibl Ophthalmol 1968;75:16-38.

4 Stallard HB. Radiotherapy for malignant melanoma of the choroid. Br f Ophthalmol 1966;50:147-55. 
5 Packer S, Stoller S, Lesser ML, et al. Long-term results of iodine 125 irradiation of uveal melanoma. Ophthalmology iodine 125 irradiati

6 Sealy R, le Roux PL, Rapley F, et al. The treatment of ophthalmic tumours with low-energy sources. $B r f$ Radio 1976;49:551-4

7 Lommatzsch PK. Results after beta-irradiation $(106 \mathrm{Ru}$ $106 \mathrm{Rh}$ ) of choroidal twenty years' experience. Am $\mathcal{F}$ Clin Oncol 1987;10:146-51.

8 Finger PT, Berson A, Szechter A. Palladium-103 plaque radiotherapy for choroidal melanoma: results of a 7-yea study. Ophthalmology 1999;106:606-13.

9 Finger PT, Buffa A, Mishra S, et al. Palladium-103 plaque radiotherapy for uveal melanoma. Clinical experience. Ophthalmology 1994;101:256-63.

10 Finger PT, Lu D, Buffa A, et al. Palladium-103 versus iodine- 125 for opthalmic plaque radiotherapy. Int $\mathcal{F}$ Radiat Oncol Biol Phys 1993;27:849-54.

11 Finger PT, Moshfeghi DM, Ho TK. Palladium 103 ophthalmic plaque radiotherapy. Arch Ophthalmol 1991; 109:1610-3.

12 Finger PT, Szechter A, Berson AM. Determination of the surgeon's absorbed dose of iodine-125 and ruthenium-106 ophthalmic plaque surgery [discussion]. Ophthalmology

13 Gunduz K, Shields CL, Shields JA, et al. Radiation retinopathy following plaque radiotherapy for posterior uveal melanoma. Arch Ophthalmol 1999;117:609-14.
14 Foss AJ, Whelehan I, Hungerford JL, et al. Predictive factors for the development of rubeosis following proton beam radiotherapy for

15 Wilson MW, Hungerford JL. Comparison of episcleral plaque and proton beam radiation therapy for the treatment of choroidal melanoma. Ophthalmology 1999; 106:1579-87.

16 Astrahan MA, Luxton G, Jozsef G, et al. Optimization of ${ }^{125} \mathrm{I}$ ophthalmic plaque brachytherapy. Med Phys 1990;17: 1053-7

17 Coleman DJ, Silverman RH, Ursea R, et al. Ultrasonically induced hyperthermia for adjunctive treatment of intraocular malignant melanoma. Retina 1997;17:109-17.

18 Finger PT. Microwave thermoradiotherapy for uveal melanoma: results of a 10-year study. Ophthalmology 1997; 104:1794-803.

19 Finger PT, Ho TK, Fastenberg DM, et al. Intraocular radiation blocking. Invest Ophthalmol Vis Sci 1990;31:1724-30.

20 Finger PT, Romero JM, Rosen RB, et al. Three-dimensional ultrasonography of choroidal melanoma: localization of ultrasonography of choroidal melanoma: localization of

21 Liggett PE, Ma C, Astrahan M, et al. Combined Localized Liggett PE, Ma C, Astrahan M, et al. Combined Localized
current field hyperthermia and irradiation for intraocular current field hyperthermia and irradiation

22 Petrovich Z, Pike M, Astrahan MA, et al. Episcleral plaque thermoradiotherapy of posterior uveal melanomas. Am $\mathcal{F}$ Clin Oncol 1996;19:207-11. 